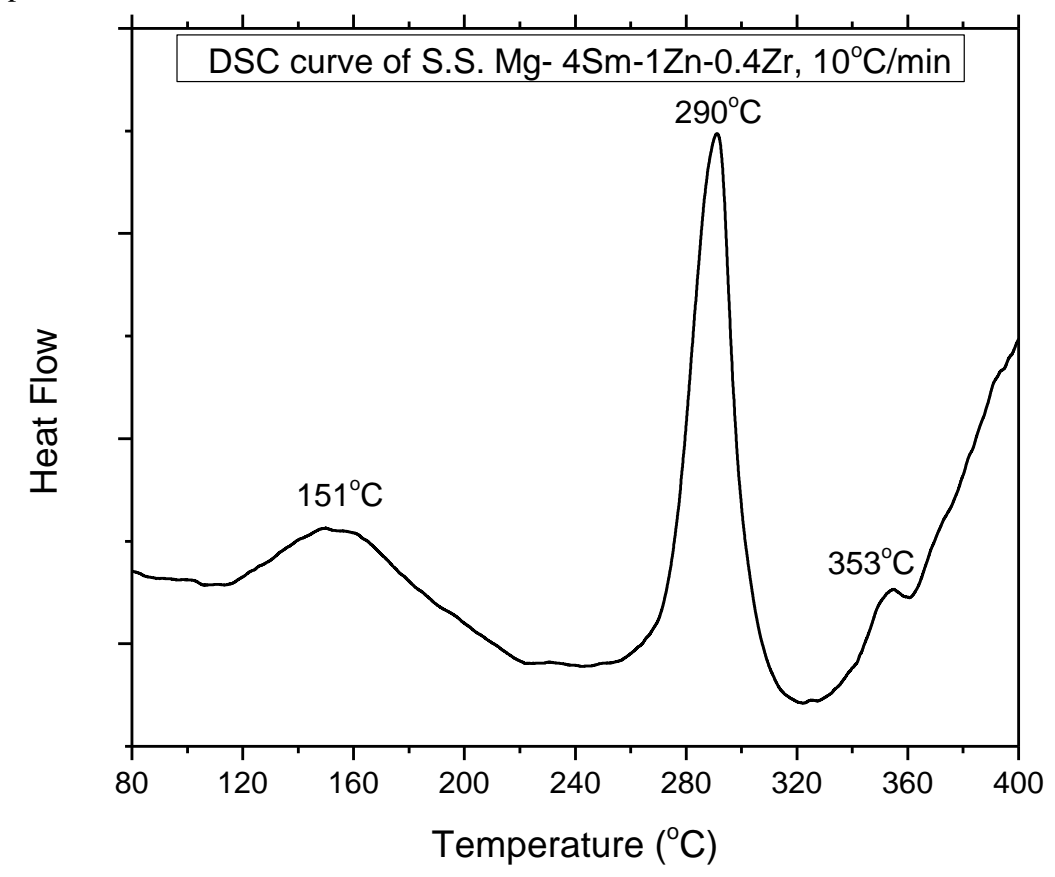

HAADF-STEM images of precipitates
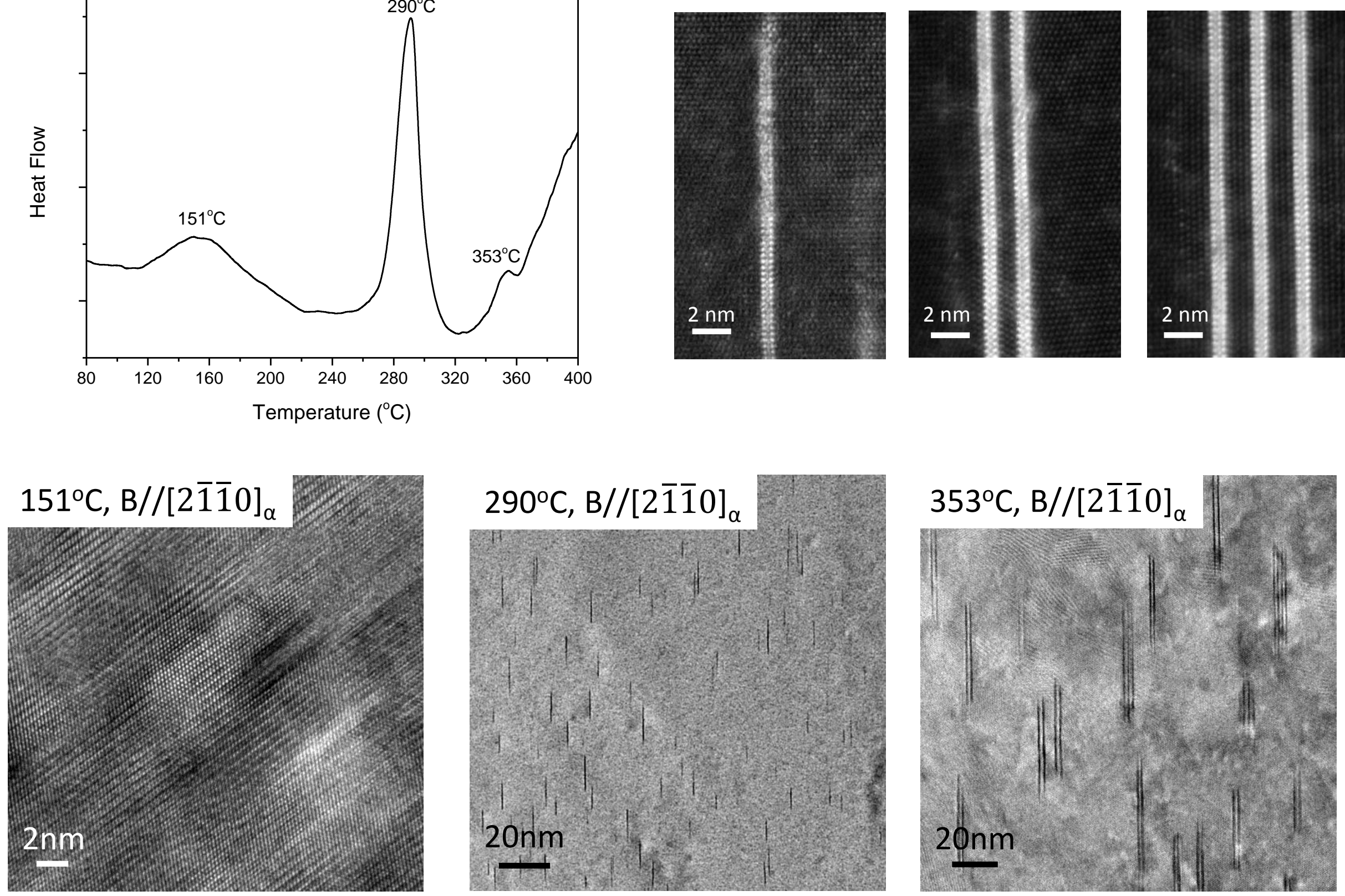

(C) 2015. This manuscript version is made available under the Elsevier user license http://www.elsevier.com/open-access/userlicense/1.0/ 


\title{
Precipitation Sequence and Kinetics in a Mg-4Sm-1Zn-0.4Zr (wt\%) alloy
}

\author{
Xiangyu Xia ${ }^{1,2 *}$, Alan A. Luo ${ }^{2,3}$, Donald S. Stone $e^{1,2}$ \\ ${ }^{1}$ Materials Science Program; University of Wisconsin - Madison, 1509 University Ave., \\ Madison, WI 53706, USA \\ ${ }^{2}$ Department of Materials Science and Engineering, University of Wisconsin-Madison, 1509 \\ University Ave, Madison, WI 53706, USA \\ ${ }^{3}$ Department of Materials Science and Engineering, The Ohio State University, $116 \mathrm{~W} .19^{\text {th }}$ Ave, \\ Columbus, OH 43210, USA
}

("Corresponding author, email: xxia5@wisc.edu, Tel: +1-662-617-5128)

\begin{abstract}
The present research presents a series of investigations into phase identification and precipitation sequence in $\mathrm{Mg}-4 \mathrm{Sm}-1 \mathrm{Zn}-0.4 \mathrm{Zr}^{1}$ alloy, using differential scanning calorimetry (DSC), transmission electron microscopy (TEM) and high angle annular dark field scanning transmission electron microscopy (HAADF-STEM). The precipitation sequence is: super saturated solid solution (S.S.S.S) $\rightarrow$ solute atom clusters $\rightarrow \gamma^{\prime \prime} \rightarrow \gamma^{\prime}$ ( $\rightarrow$ stacking faults) $\rightarrow \gamma$. Structure of $\gamma^{\prime}$ ' has been determined as an ordered hexagonal GP zone, $a=0.556 \mathrm{~nm}, \mathrm{c}=0.414 \mathrm{~nm}$. $\gamma^{\prime}$ is composed of several $\gamma$ " layers. Kinetic studies show that quenched-in vacancies play an important role in the formation of solute clusters, while the growth of both precipitates are diffusion controlled. Analysis of microstructure evolution suggests that nucleation of $\gamma^{\prime}$ happens near existing $\gamma$ " precipitates.
\end{abstract}

Keywords: $M g-S m-Z n-Z r$ alloys, precipitation, heat treatment, transmission electron microscopy, scanning transmission electron microscopy, kinetics

\section{Introduction}

Magnesium alloys have attracted considerable interest in transportation industries due to their low density, high specific stiffness, excellent castability, and other favorable attributes [1-4]. Addition of rare earth (RE) elements into $\mathrm{Mg}$ significantly improves strength and creep resistance through solid solution strengthening, precipitation hardening, and/or texture randomization $[5,6]$. Studies on correlations between mechanical properties and microstructure evolution in several $\mathrm{Mg}-\mathrm{RE}$ alloys, including yttrium $(\mathrm{Y})$, cerium $(\mathrm{Ce})$, neodymium $(\mathrm{Nd})$, and gadolinium $(\mathrm{Gd})$, have been reported [7-12]. Samarium (Sm) is considered as promising alloying

\footnotetext{
${ }^{1}$ All composition in wt.\% except otherwise stated.
} 
elements for $\mathrm{Mg}$ alloy optimization, due to its high solid solubility at high temperature $\left(\sim 530^{\circ} \mathrm{C}\right)$ and eutectic reaction near $\mathrm{Mg}$ side [13, 14]. Age-hardening response was reported in $\mathrm{Mg}-\mathrm{Sm}-\mathrm{Zr}$ alloys [15], in which ultimate tensile strength (UTS) improved dramatically from 172MPa to $286 \mathrm{MPa}$, while elongation decreased only slightly, $9.2 \%$ to $8.4 \%$. The dominant precipitate was reported as $\beta "\left(\mathrm{Mg}_{3} \mathrm{Sm}, \mathrm{D} 019, \mathrm{a}=0.642 \mathrm{~nm}, \mathrm{c}=0.521 \mathrm{~nm}\right)$, lying on $\{11 \overline{2} 0\}$ prismatic planes $[15$, 16]. Although contradictory reports can be found [17] stating the key precipitate is $\beta^{\prime}\left(\mathrm{Mg}_{7} \mathrm{Sm}\right.$, orthorhombic, $a=0.64 \mathrm{~nm}, b=3.334 \mathrm{~nm}, c=0.52 \mathrm{~nm}$ ), it can nevertheless be concluded that the prismatic $\beta$ precipitates dominate the aging process [18] in $\mathrm{Mg}-\mathrm{Sm}-\mathrm{Zr}$ alloys.

Moderate $(<0.5 \%)$ addition of $\mathrm{Zn}$ enhances $\beta$-series formation, which is believed to increase creep resistance in Mg-RE alloys, while higher addition introduces $\gamma$-series precipitates that decrease aging response [18-22]. For example Yuan and Zheng [23, 24] investigated the effect of $\mathrm{Zn}$ on the aging behavior of $\mathrm{Mg}-\mathrm{xZn}-3 \mathrm{Sm}-0.5 \mathrm{Gd}$ alloys $(\mathrm{x}=0,0.3,0.6)$, and found that with increase of $\mathrm{Zn}$, the dominant strengthening precipitate changes from $\beta$ " to $\beta$ ' (orthorhombic, $\mathrm{a}=0.64 \mathrm{~nm}, \mathrm{~b}=2.223 \mathrm{~nm}, \mathrm{c}=0.52 \mathrm{~nm}$ ), and then to $\gamma^{\prime \prime}(\mathrm{HCP}, \mathrm{a}=0.556 \mathrm{~nm})$. Similar aging response was reported in $\mathrm{Mg}-\mathrm{Sm}-\mathrm{Zn}-\mathrm{Zr}$ [25], where the precipitation sequence was reported as super saturated solid solution (S.S.S.S) $\rightarrow$ solute atom clusters $\rightarrow \gamma^{\prime}$ " (Guinier Preston zone (GP zone), $\mathrm{a}=0.556 \mathrm{~nm}) \rightarrow \gamma^{\prime}$ (hexagonal, $\left.\mathrm{a}=0.556 \mathrm{~nm}, \mathrm{c}=0.521 \mathrm{~nm}\right) \rightarrow \gamma(\mathrm{FCC}, \mathrm{a}=0.73 \mathrm{~nm})$. The main strengthening precipitate is $\gamma$ ", which was identified as a single solute atom layer. It should be noted that for the structure of $\gamma$ ", while most researchers considered it as an ordered GP zone from diffraction pattern and assumed $\mathrm{c}=\mathrm{c}_{\mathrm{Mg}}=0.521 \mathrm{~nm}$, Nie [26] identified $\mathrm{c}=0.444 \mathrm{~nm}$, by direct observation through high angle annular dark field scanning transmission electron microscopy (HAADF-STEM). Such a discrepancy indicates that modification is necessary to determine the structure of $\gamma "$.

The dominance of $\gamma$-series precipitates, lying on (0001) basal planes, results in decrease in age hardening response as $\mathrm{Zn}$ content is increased, because the $\gamma$-series are less effective at impeding dislocations than the $\beta$-series precipitates are. Thus a clear understanding of the $\gamma$-series and the conditions under which they dominate is of essential importance for development of Mg-RE-Zn$\mathrm{Zr}$ alloys. Although there have been some investigations on mechanical properties and microstructure evolution of $\mathrm{Mg}-\mathrm{Sm}-\mathrm{Zn}-\mathrm{Zr}$ alloys, limited work is focused on precipitation kinetics of $\gamma$-series, and structures of them remain controversial. In this work, we present a systematical study on the nature and kinetics of $\gamma$ precipitates, using transmission electron microscopy (TEM), HAADF-STEM, and differential scanning calorimetry (DSC), aiming to provide a comprehensive understanding of the microstructure evolution, properties of metastable precipitates, and kinetics of precipitation in relative high $\mathrm{Zn}$ content $\mathrm{Mg}-\mathrm{RE}-\mathrm{Zn}-\mathrm{Zr}$ alloys, for further alloy design and processing optimization.

\section{Experiment}

Sample alloy with a target composition of $\mathrm{Mg}-4 \mathrm{Sm}-1 \mathrm{Zn}-0.4 \mathrm{Zr}$ were prepared using commercially pure $\mathrm{Mg}, \mathrm{Zn}$ (>99.9\%), Mg-20Sm and $\mathrm{Mg}-30 \mathrm{Zr}$ master alloy ingots. The alloying ingredients were melted in a steel crucible, cast into a steel mold preheated to $230^{\circ} \mathrm{C}$ under protection of $\mathrm{SF}_{6} / \mathrm{CO}_{2}$, and then degassed by bubbling pure Argon for about $20 \mathrm{~min}$ at $740^{\circ} \mathrm{C}$. The chemical composition of the as-cast sample alloy was analyzed by Inductively Coupled Plasma Mass Spectrometry (ICP-MS), and determined as Mg-4.36Sm-1.27Zn-0.39Zr. For protection 
against oxidation during heat treatment, all samples were wrapped with tantalum foil and sealed in quartz tubes back-filled with high-purity He atmosphere (>99.999\%) before heating.

Solid solution treatment was conducted at $520^{\circ} \mathrm{C}$ for 8 hours, followed by quenching in room temperature (RT) water. The solid solutionized (S.S) samples were subsequently cut to small pieces of around $2 \times 2 \times 1 \mathrm{~mm}^{3}(\sim 20 \mathrm{mg})$, then cleaned with ethanol before DSC tests, which were performed on a DQ100 Differential Scanning Calorimeter from TA instruments. Standard aluminum pans were used as references as well as to encapsulate the samples. During the measurement, samples underwent cyclic thermal treatment from $40^{\circ} \mathrm{C}$ to $450^{\circ} \mathrm{C}$, for three cycles, with 4 different heating rates of $5,10,15$ and $20^{\circ} \mathrm{C} / \mathrm{min}$, respectively. The third cycle (over-aged condition) was used to establish a background, which was subtracted from the first cycle (S.S condition).

To identify precipitates formed in this process, S.S samples were heated at $10^{\circ} \mathrm{C} / \mathrm{min}$ to temperatures where exothermic or endothermic peaks were measured in the $10^{\circ} \mathrm{C} / \mathrm{min}$ DSC curve, held for 3 minutes, then quenched in RT water. These samples were subsequently analyzed by Transmission Electron Microscopy (TEM, FEG-Tecnai-TF30, 300kV) and Scanning Transmission Electron Microscopy (STEM, TITAN, 200kV) to identify the precipitation reactions that dominate at those peak temperatures. For sample preparation, $1000 \mu \mathrm{m}$-thick slices were cut from these bulk samples and ground down to $\sim 50 \mu \mathrm{m}$, using Allied Multiprep machine with diamond lapping films $(15,6,3,1$, then $0.1 \mu \mathrm{m}$ particle size). The polished samples were then ion milled with Fischione $1050,\left(3.0 \mathrm{kV}\right.$ ion gun energy and $5^{\circ}$ milling angle). Finally, $0.6 \mathrm{kV}$ ion gun energy was used to clean up surface.

\section{Results and Discussion}

\section{$\underline{\text { Precipitation Sequence }}$}

Fig. 1 shows the DSC curve of S.S sample at heating rate of $10^{\circ} \mathrm{C} / \mathrm{min}$. Exothermal peaks are found at approximately 151,290 , and $353^{\circ} \mathrm{C}$, representing three different precipitation reactions. Figs. 2a and b show HRTEM and corresponding Fast Fourier Transform (FFT) images of sample alloy heated to peak temperature $151^{\circ} \mathrm{C}$, on zone axis $[0001]_{\alpha}$ and $[2 \overline{1} \overline{1} 0]_{\alpha}$, respectively. HRTEM image near [0001 $]_{\alpha}$ show dark areas randomly distributed in the grain without specific diffraction features, tentatively identified as clusters of solute atoms. With zone axis near $[2 \overline{1} \overline{1} 0]_{\alpha}$, fig. $2 \mathrm{~b}$ reveals that solute atoms cluster to form multiple atom layers with streaks in the corresponding FFT image.

Microstructures and corresponding diffraction patterns of the sample alloy annealed at $290^{\circ} \mathrm{C}$ are shown in figs. $3 a-b$, taken near zone axis $[0001]_{\alpha}$ and $[2 \overline{1} \overline{1} 0]_{\alpha}$, respectively. From fig. $3 a$, no obvious features can be observed in TEM bright field image. In corresponding diffraction pattern extra spots are found at $1 / 3$ and $2 / 3\{2 \overline{1} \overline{1} 0\}_{\alpha}$, representing a phase with hexagonal structure and $\mathrm{a}=0.556 \mathrm{~nm}$. Fig. $3 \mathrm{~b}$ reveals $5-20 \mathrm{~nm}$ long and $1-2 \mathrm{~nm}$ thick needle-like precipitates, lying on $(0001)_{\alpha}$ basal planes. Strong streaks are present along $\{0001\}_{\alpha}$ in the corresponding diffraction pattern, indicating a GP zone structure. Atomic structure of this needle-like precipitate is shown by HAADF-STEM image in Fig.3c. The contrast of HAADF-STEM image is proportional to square of the atomic number of the element. Thus the light spots represent $\mathrm{Sm}$ or $\mathrm{Zn}$ atom columns. Apparently, instead of a single solute atom layer as reported in [25], two Sm/Zn layers 
lie on the $\mathrm{Mg}$ matrix, with one $\mathrm{Zn} / \mathrm{Mg}$ layer in between. Compared with $\mathrm{Mg}$ atoms $(0.137 \mathrm{~nm})$, smaller $\mathrm{Zn}$ atoms $(0.120 \mathrm{~nm})$ release the strain from the large $\mathrm{Sm}$ atoms $(0.181 \mathrm{~nm})$. Such a structure, together with diffraction patterns, resembles $\gamma$ " in Mg-Gd-Zn alloys, and could be determined as ordered hexagonal, $a=0.556 \mathrm{~nm}$. It is named as $\gamma$ " in this work. The orientation relationship with $\mathrm{Mg}$ matrix is such that $[10 \overline{1} 0]_{\gamma}, / /[2 \overline{1} \overline{1} 0]_{\alpha}$. Taking c constant of $\mathrm{Mg}$ as $0.521 \mathrm{~nm}$ [27], the distance between Sm layers could be measured directly as $c=0.414( \pm 9) \mathrm{nm}$, which is close to that reported for $\gamma$ " in $\mathrm{Mg}-\mathrm{Gd}-\mathrm{Zn}$ system $(0.444 \mathrm{~nm})$. The chemical composition is derived from the crystal structure as $(\mathrm{Mg}, \mathrm{Zn})_{5} \mathrm{Sm}$, though a full crystal structure is not observed since $\gamma$ " has a GP zone structure.

Diffraction patterns of phase product of transition reaction at $353^{\circ} \mathrm{C}$ are shown in figs. $4 \mathrm{a}$ and $\mathrm{b}$, with beam parallel to [0001 $]_{\alpha}$ and $[2 \overline{1} \overline{1} 0]_{\alpha}$, respectively. Similar extra spots at $1 / 3$ and $2 / 3\{2 \overline{1} \overline{1} 0\}_{\alpha}$ are present when $\mathrm{B} / /[0001]_{\alpha}$, and similar streaks can be found along $\{0001\}_{\alpha}$ when $\mathrm{B} / /[2 \overline{1} \overline{1} 0]_{\alpha}$. Such diffraction features suggest presence of a phase with a structure similar to $\gamma$ ". Microstructure observations reveal laminate structures of $15-80 \mathrm{~nm}$ in length, as shown in fig.4c and d. Fig.4e and f show that each laminate structure is composed of two or more layers of solute atoms, which have the same structure as $\gamma$ ", making them GP II zones. In this work they are named as $\gamma^{\prime}$. Apparently formation of $\gamma^{\prime}$ might involve nucleation and growth of a new layer of $\gamma^{\prime \prime}$ next to the existing $\gamma$ ". In this structure, the adjacent $\gamma$ " layers are separated by 3 or 4 layers of $\mathrm{Mg}$ atoms, thus the distance between are $2 \mathrm{c}_{\mathrm{Mg}}$ or $2.5 \mathrm{c}_{\mathrm{Mg}}$.

It was pointed out in [25] that the equilibrium precipitate in $\gamma$ series is $\gamma(\mathrm{FCC}, \mathrm{a}=0.74 \mathrm{~nm})$, but in this work there is no sign of $\gamma$, except on the grain boundaries, as seen in fig.5a taken from the $353^{\circ} \mathrm{C}$ sample. From the FFT image (fig. $5 \mathrm{~b}$ ) the beam is parallel to $[001]_{\gamma}$, and the FCC structure could thus be determined. Besides, the precipitate free zone (PFZ) with 200nm thickness could be found near the grain boundary, which is attributed to depletion of vacancies and solute atoms near grain boundaries during heat treatment. Overall, the DSC signal increases steadily after $330^{\circ} \mathrm{C}$ (fig.1), which is probably related to formation of $\gamma$.

\section{$\underline{\text { Precipitation Kinetics }}$}

The DSC curves of S.S samples at four heating rates are presented in fig. 6. Peak temperatures increase with increasing heating rates, indicating these precipitation reactions are kinetically controlled. Kinetic properties of these precipitates can thus be calculated based on John-MehlAvrami-Kilmogoroc (JMAK) relation [28-32], in which volume fraction of precipitate phases is related to kinetic laws of growth. For non-isothermal processes, several methods have been developed based on this relation [33-37] for calculation of kinetic parameter. Among them, the Kissinger method [35], which takes into account the shift of peak positions under different heating rates, has been most commonly used. Here, the relation between peak temperature $T_{p}$ and heating rate $\phi$ is

$\ln \frac{T_{p}^{2}}{\phi}=\frac{Q}{R T_{p}}+C$ 
Where $\mathrm{R}$ is gas constant, $C$ is a constant, $Q$ is activation energy and $Q=\frac{Q_{N}+n Q_{G}}{n+1}$ [38], in which $Q_{N}$ is nucleation activation energy and $Q_{G}$ is growth activation energy. $n$ is time exponent.

According to Farjas [38], the general equation for calculation of the fraction of transformed phases for non-isothermal processes can be written as:

$X=1-\exp \left\{\left[-k_{0} C \frac{Q}{R \phi} p\left(\frac{Q}{R T}\right)\right]^{n+1}\right\}$

Here $X$ is the fraction of transformed phase, $p(x)=\int_{x}^{\infty} \frac{\exp (-\mu)}{\mu^{2}} d \mu$. With a first-order approximation,

$p(x) \approx \frac{\exp (-x)}{x^{2}}$

In DSC analysis, $X_{i}(t)$, the fraction of transformed phase at peak i (phase transition reaction i) as a function of temperature, can be defined by using the following equation

$X_{i}(t)=\frac{A_{i}(T)}{A_{i}}$

$A_{i}$ represents total area of the peak i, and $A_{i}(T)$ is the area of the peak i at temperature T. The fraction of transform phase can thus be represented as a function of temperature.

Rearranging $\mathrm{Eq}(2)$ and substitute $\mathrm{p}$ with $\mathrm{Eq}(3)$ gives [38]

$\ln [-\ln (1-X)]=(n+1) \ln \left[\frac{\exp \left(-\frac{Q}{R T}\right)}{\left(\frac{Q}{R T}\right)^{2}}\right]+(n+1) \ln \left(k_{0} C \frac{Q}{R \phi}\right)$

Since $(n+1) \ln \left(k_{0} C \frac{Q}{R \phi}\right)$ is constant under the same heating rate for the same phase transition reaction, one can plot $\ln [-\ln (1-X)] \operatorname{vs} \ln \left[\frac{\exp \left(-\frac{Q}{R T}\right)}{\left(\frac{Q}{R T}\right)^{2}}\right]$ and the slope gives $n+1$.

Calculation results are listed in Table.1, along with precipitates' morphologies and structures. For the $151{ }^{\circ} \mathrm{C}$ peak, phase product is solute atom clusters, and the corresponding activation energy is $75 \mathrm{~kJ} / \mathrm{mol}$. Such a value is much lower than the activation energy reported for selfdiffusion $(134 \mathrm{~kJ} / \mathrm{mol}[39])$ of $\mathrm{Mg}$, and higher than that for vacancy migration $(48 \mathrm{~kJ} / \mathrm{mol}[40])$. Therefore the migration of quenched in vacancies plays an important role in the formation of these clusters. This conclusion is supported by the calculated time exponent, i.e., 0.21. This value suggests that the nucleation happens instantaneously [41], which is expected because of its coherent nature, and growth happens with the help of defects or vacancies [41].

The activation energies of $\gamma$ " is calculated as $132 \mathrm{~kJ} / \mathrm{mol}$, indicating it is diffusion-controlled growth and quenched-in vacancies are no longer effective. Growth of $\gamma$ " is shown in Fig. 7a-d for alloys annealed at $340^{\circ} \mathrm{C}$ for $3 \mathrm{~min}, 353^{\circ} \mathrm{C}$ for $1 \mathrm{~min}, 3 \mathrm{~min}, 6 \mathrm{~min}$, respectively, all on zone axis 


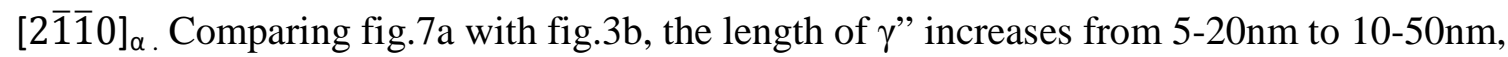
while the thickness remains unchanged, indicating diffusional growth in one dimension and agreeing to the activation energy. The time exponent of $\gamma$ " is 1.56 , close to that reported for $\gamma$ " in $\mathrm{Mg}-\mathrm{Nd}-\mathrm{Zn}$ system (1.5) [20], and corresponding to growth from small particles [42]. This is to be expected since pre-existing solute atom clusters work as nuclei for $\gamma^{\prime \prime}$. The length of $\gamma^{\prime}$ grows from $15-80 \mathrm{~nm}$ to $20-100 \mathrm{~nm}$ with increasing annealing time as shown in fig.7b-d,, corresponding to diffusional growth indicated by the calculated activation energy of $\gamma$, i.e. $140 \mathrm{~kJ} / \mathrm{mol}$. It is difficult to assess the time exponent using the Avrami analysis because the peak is too small compared to the background.

It is interesting to notice that in addition to $\gamma^{\prime}$, a long $(>100 \mathrm{~nm})$, thin $(\sim 1-5 \mathrm{~nm})$ linear feature could be observed after annealing at $353^{\circ} \mathrm{C}$ for $6 \mathrm{~min}$, as labeled with red arrow in fig. $7 \mathrm{~d}$. Being similar to stacking faults reported in Mg-Gd-Zn system [44], this feature is tentatively determined as stacking fault. Lack of observation of this feature during age hardening [25] indicates that it has a very low number density and little effect on age hardening in $\mathrm{Mg}-\mathrm{Sm}-\mathrm{Zn}$ $\mathrm{Zr}$ alloys.

\section{Conclusion}

1. Precipitation sequence in a high-Zn Mg-Sm-Zn-Zr alloy has been identified as: S.S.S.S $\rightarrow$ solute atom clusters $\rightarrow \gamma^{\prime \prime} \rightarrow \gamma^{\prime}(\rightarrow$ stacking faults $) \rightarrow \gamma$. Structure of $\gamma^{\prime \prime}$ has been determined as an ordered hexagonal GP zone, $\mathrm{a}=0.556 \mathrm{~nm}$ and the constant has been measured directly with HAADF-STEM observation: $c=0.414 \mathrm{~nm}$. $\gamma^{\prime}$ has a GP II structure and is composed of several $\gamma$ ” layers.

2. Kinetic studies show that quenched-in vacancies play an important role in the formation of solute clusters, while the growth of $\gamma^{\prime \prime}$ and $\gamma^{\prime}$ are diffusion controlled under equilibrium vacancy concentrations. Analysis of microstructure evolution suggests that nucleation of $\gamma^{\prime}$ happens near existing $\gamma$ " precipitates.

\section{Acknowledgement}

The authors acknowledge financial support from National Science Foundation (Award No. 1005762), use of instrumentation supported by the UW MRSEC (DMR-1121288) and the UW NSEC (DMR-0832760). We would also like to thank Prof. Xiaoqin Zeng and Ms. Ran Chen from Department of Materials Science and Engineering of Shanghai Jiaotong University, for providing alloy samples.

\section{References}

[1]. Bamberger M, Dehm G, "Trends in the Development of New Mg Alloys", Annu. Rev. Mater.Res.38 (2008)505-33 
[2]. Luo A.A, "Recent magnesium alloy development for elevated temperature applications", International Materials Review. 49 (2004)13-30

[3]. Pekguleryuz M.O, Kaya A.A. In: K.U.Kainer, editor. Magnesium alloys and their Applications. Germany, Wiley-VCH Verlag GmbH, 2003, pp.74

[4]. Luo A.A, Mishra R.K, Powell B.R, Sachdev A.K, "Magnesium Alloy Development for Automotive Applications", Materials Science Forum. 706-709 (2012)69-82

[5]. Rokhlin L.L, Magnesium Alloys Containing Rare Earth Metals: Structure and Properties. CRC Press, 2003

[6]. Moreno. I.P, Nandy T.K, Jones J.W, Allison J.E, Pollock T.M, "Microstructure and Creep Behavior of a Die Cast Magnesium-Rare Earth alloy", Magnesium Technology 2002, pp.111116

[7]. K. Hantzsche, J.Bohlen, J.Wendt, K.Kainer, S.Yi, D.Letzig, "Effect of rare earth additions on microstructure and texture development of magneiusm alloy sheets", Scripta Mater. 63 (2010)725-730

[8]. R.K. Mishra, A.K.Gupta, P.R.Rao, A.K.Sachdev, A.Kumar, A.Luo, "Influence of cerium on the texture and ductility of magnesium extrusions", Scripta Mater. 59 (2008) 562-565

[9]. D.Wu, R.S.Chen, E.H.Han, "Excellent room-temperature ductility and formability of rolled Mg-Gd-Zn alloys sheets", J. Alloys Comp. 509 (2011) 2856-2863

[10]. T.J. Pike, B. Noble, "The formation and structure of precipitates in a dilute mageniusmneodymium alloy", J. the Less-Common Met. 30 (1973) 63-74

[11]. A.Sanaty-Zadeh, X. Xia, A. A. Luo, D. S. Stone. "Precipitation evolution and kinetics in a magnesium-neodymium-zinc alloy", J. Alloys Comp. 583(2014) 434-440

[12]. L. Ma, R. K. Mishra, M. P. Balogh, L. Peng, A. A. Luo, A.K. Sachdev, W. Ding, "Effect of $\mathrm{Zn}$ on the microstructure evolution of extruded Mg-3Nd(-Zn_-Zr(wt\%) alloys", Mater. Sci. Eng. A 543 (2012) 12-21

[13]. X. Xia, A Sanaty-Zadeh, C Zhang, X Q. Zeng, A A. Luo, Y A. Chang, D S. Stone, "Thermodynamic modeling and experimental investigation of the magnesium-zinc-samarium alloys", J Alloys Comp, 593 (2014) 71-78

[14]. Drit M.E, Rokhlin L.L, Abrikina N.P, Kinzhibalo V.V, Tyvanchuk A.T, "PHASE

EQUILIBRIA IN THE MG-SM-ZN SYSTEM”, Izvestiya Akademii Nauk SSSR. Metally. 6

(1985)194-200

[15]. Zhenyan Zhang, phd thesis, Shanghai Jiaotong University, 2009

[16]. Xin Su, master thesis, Shanghai Jiaotong University, 2013

[17]. M Nishijima, K Hiraga, M Yamasaki, Y Kawamura, "Characterization of Precipitates in Mg-Sm Alloy Aged at 200 C, Studied by High-Resolution Transmission Electron Microscopy and High-Angle Annular Detector Dark-Field Scanning Transmission Electron Microscopy", Materials transactions, 50(07) (2009) 1747-1752.

[18]. J Nie, "Precipitation and Hardening in Magnesium Alloys", Metallurgical and Materials Transtractions A, 43A (2012) 3891-3939

[19]. E. F. Emley, Principle of Magnesium Technology, Pergamon Press Ltd, 1966, p. 1013

[20]. P.A.Nuttall, T.J.Pike, B.Noble, "Metallography of dilute Mg-Nd-Zn alloys", Metallography, 13 (1980) 3-20

[21]. D.-H.Ping, K.Hono, J.F.Nie, “Atom Probe Characterization of plate-like precipitates in a Mg-RE-Zn-Zr casting alloy”, Scripta Materialia, 48 (2003) 1017-1022

[22]. R.Wilson, C.J.Bettles, B.C.Muddle, J.F.Nie, "Precipitation hardening in Mg-3wt\%Nd(-Zn) casting alloys", Materials Science Forum, 419-422 (2003) 267-272 
[23]. M Yuan, Z Zheng, "Effects of $\mathrm{Zn}$ on the microstructure and mechanical properties of Mg3Sm-0.5Gd-xZn-0.5Zr (x=0, 0.3, 0.6) alloy", J Alloys Comp, 590 (2014) 355-361

[24]. M Yuan, Z Zheng, "Microstructure and mechanical properties of a Mg-Sm-Gd-Zn-Zr Alloy processed by heat treatment", Metallorgr. Microstruct. Anal. 3 (2014) 131-137

[25]. X Xia, A Sanaty-Zadeh, R Chen, X Zeng, A A. Luo, D S. Stone, "Precipitation sequence in a Mg-Sm-Zn-Zr alloy", Magnesium Technology 2015, 367-373

[26]. J. F. Nie, K. Oh-ishi, X. Gao, K. Hono, "Solute segregation and precipitation in a creepresistant Mg-Gd-Zn alloy", Acta Mater, 56(2008) 6061-76

[27]. Okamoto H, etc, Mg-Sm Phase Diagram, ASM Alloy Phase Diagrams Center, P. Villars, editor-in-chief; H. Okamoto and K. Cenzual, section editors;

httpwww1.asminternational.orgAsmEnterpriseAPD, ASM International, Materials Park, OH, 2006

[28]. J.D. Verhoeven, Fundamental of Physical Metallurgy, J.Wiley e Sons, NY (1975), Chp 5

[29]. W.A.Johnson, K.E.Mehl "Reaction kinetics in processes of nucleation and growth", Trans. Aime 135 (1939) 396-415

[30]. M. Avrami, "Kinetics of phase change. I General theory", J. Chem. Phy 7 (1939) 11031112

[31]. M. Avrami, "Kinetics of phase change. II transformation-time relations for random distribution of nuclei", J. Chem. Phy 8 (1940) 212-224

[32]. M. Avrami, "Kinetics of phase change. III Granulation, phase change, and microstructure", J. Chem. Phy 9 (1941) 177-184

[33]. F.L.Cumbrera, F.Sanchez-Bajo, "The use of the JMAYK kinetic equation for the analysis of solid-state reactions: critical considerations and recent interpretations", Thermochimica Acta 266 (1995) 315-330

[34]. T.Kemeny, J.Sestak, "Comparison of crystallization kinetics determined by isothermal and non-isothermal methods", Thermochimica Acta 110(1987) 113-129

[35]. H.Kissinger, "Reaction kinetics in differential thermal analysis", Analytical Chemistry, 29 (1957) 1702-1706

[36]. A.Munoz, F.L.Cumbrera, "Kinetic study of isothermal and continuous heating crystallization in $\mathrm{Se}_{100-}{ }_{\mathrm{B}} \mathrm{Bi}_{\mathrm{x}}(\mathrm{x} \leqslant 8)$ glasses." Thermochimica Acta, 144(1989) 123-139

[37]. J Malek, "Applicability of the master plots in kinetic analysis of non-isothermal data", Thermochimica Acta 147(1989) 377-385

[38]. J. Farjas, P.Roura, "Modification of the Kolmogorov-Johnson-Mehl-Avrami rate equation for non-isothermal experiments and its analytical solution", Acta Mater, 54 (2006) 5573-5579 [39]. G Neumann, C Tuijn. Self-diffusion and impurity diffusion in pure metals: handbook of experimental data[M]. Elsevier, 2011.

[40]. T.J.Pike, B.Noble, "The formation and structure of precipitates in a dilute magnesiumneodymium alloy", 30 (1973) 63-74

[41]. C. W. Price, "Use of Kolmogorov-Johnson-Mehl-Avrami kinetics in recrystallization of metals and crystallization nof metallic glasses", Acta Metall Mater, 38(1990) 727-738

[42]. J. W. Christain, The theory of Transformations in Metals and Alloys, Part I, Pergamon Press, Oxford, 1975, $2^{\text {nd }}$ edn

[43]. T. Sato, A. Kamio, "High resolution electron microscopy of phase decomposition microstructures in aluminium-based alloys", Mater Sci Eng A, 146(1991) 161-180 
[44]. K. Saito, A. Yasuhara, K. Hiraga, "Microstructural changes of Guinier-Preston zones in an Mg-1.5at\%Gd-1at\%Zn alloy studied by HAADF-STEM technique", J Alloys Comp, 509(2011) 2031-2038

Table.1. Characteristics and kinetic parameters of metastable phases in $\mathrm{Mg}-4 \mathrm{Sm}-1 \mathrm{Zn}-0.4 \mathrm{Zr}$

\begin{tabular}{|c|c|c|c|c|}
\hline Phase & Structure & Morphology & $\begin{array}{c}\text { Activation } \\
\text { energy } \\
(\mathrm{kJ} / \mathrm{mol})\end{array}$ & $\begin{array}{c}\text { Time } \\
\text { exponent }\end{array}$ \\
\hline $\begin{array}{l}\text { Solute atom } \\
\text { clusters }\end{array}$ & - & - & 75 & 0.21 \\
\hline$\gamma "$ & $\begin{array}{l}\text { Ordered hexagonal (GP I) } \\
\begin{array}{c}\mathrm{a}=0.556 \mathrm{~nm} \\
\mathrm{c}=0.414 \mathrm{~nm}\end{array}\end{array}$ & $\begin{array}{l}\text { Needle-like } \\
\text { 5-20nm long } \\
1-2 \mathrm{~nm} \text { thick }\end{array}$ & 132 & 1.56 \\
\hline$\gamma$ & $\begin{array}{l}\text { Ordered hexagonal (GP II) } \\
\qquad \begin{array}{c}a=0.556 \mathrm{~nm} \\
\mathrm{c}=0.414 \mathrm{~nm}\end{array}\end{array}$ & $\begin{array}{c}\text { Plate } \\
\text { 20-80nm long } \\
\text { 5-15nm thick }\end{array}$ & 140 & - \\
\hline
\end{tabular}

Figure captions

Fig.1. DSC curve of S.S sample alloy at $10^{\circ} \mathrm{C} / \mathrm{min}$

Fig.2. TEM Bright Field images and corresponding Fast Fourier Transform images of sample alloy annealed $151^{\circ} \mathrm{C}(\mathrm{a}): \mathrm{B} / /[0001]_{\alpha} ;(\mathrm{b}): \mathrm{B} / /[2 \overline{1} \overline{1} 0]_{\alpha}$

Fig.3. TEM Bright Field image and corresponding Diffraction Patterns of sample alloy annealed $290^{\circ} \mathrm{C}$ at $10^{\circ} \mathrm{C} / \mathrm{min}(\mathrm{a}): \mathrm{B} / /[0001]_{\alpha} ;(\mathrm{b}): \mathrm{B} / /[2 \overline{1} \overline{1} 0]_{\alpha} ;(\mathrm{c})$ : HAADF-STEM image of the same sample, $\mathrm{B} / /[2 \overline{1} \overline{1} 0]_{\alpha}$

Fig.4. Diffraction Patterns of sample alloy annealed $353^{\circ} \mathrm{C}$ at $10^{\circ} \mathrm{C} / \mathrm{min}(\mathrm{a}): \mathrm{B} / /[0001]_{\alpha}$; (b): $\mathrm{B} / /[2 \overline{1} \overline{1} 0]_{\alpha} ;(\mathrm{c})$ : TEM Bright Field image of the same sample, B//[2 $\left.\overline{1} \overline{1} 0\right]_{\alpha} ;(\mathrm{d}-\mathrm{f}):$ HAADF-STEM image of the same sample, $\mathrm{B} / /[2 \overline{1} \overline{1} 0]_{\alpha}$

Fig.5. TEM Bright Field image of the $353^{\circ} \mathrm{C}$ sample alloy (a): grain boundary, B//[2 $\left.\overline{1} \overline{1} 0\right]_{\alpha}$; (b): HRTEM of the grain boundary and corresponding Fast Fourier Transform (FFT) image 
Fig.6. DSC curves of S.S sample alloys at $5,10,15,20^{\circ} \mathrm{C} / \mathrm{min}$

Fig.7. TEM Bright Field image of the sample alloys annealed at (a): $340^{\circ} \mathrm{C}$ for $1 \mathrm{~min}$; (b): $353^{\circ} \mathrm{C}$ for $1 \mathrm{~min}$; (c): $353^{\circ} \mathrm{C}$ for $3 \mathrm{~min}$; (d): $353^{\circ} \mathrm{C}$ for $6 \mathrm{~min}, \mathrm{~B} / /[2 \overline{1} \overline{1} 0]_{\alpha}$

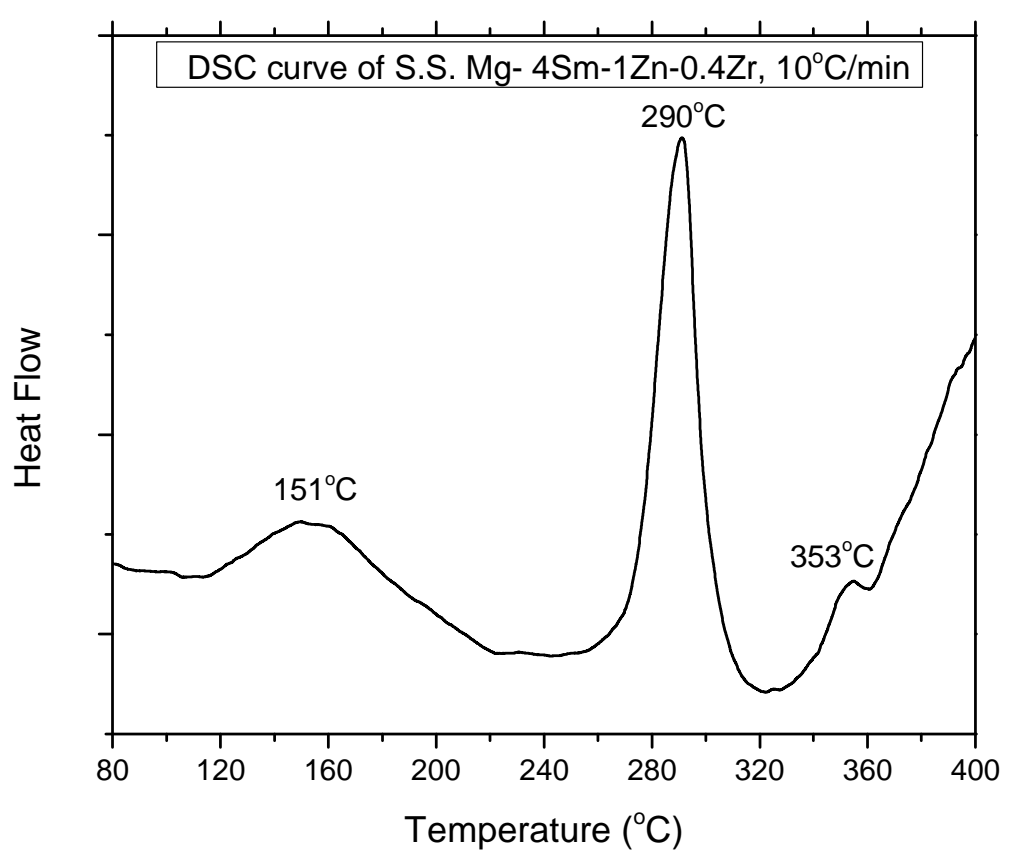

Fig.1 


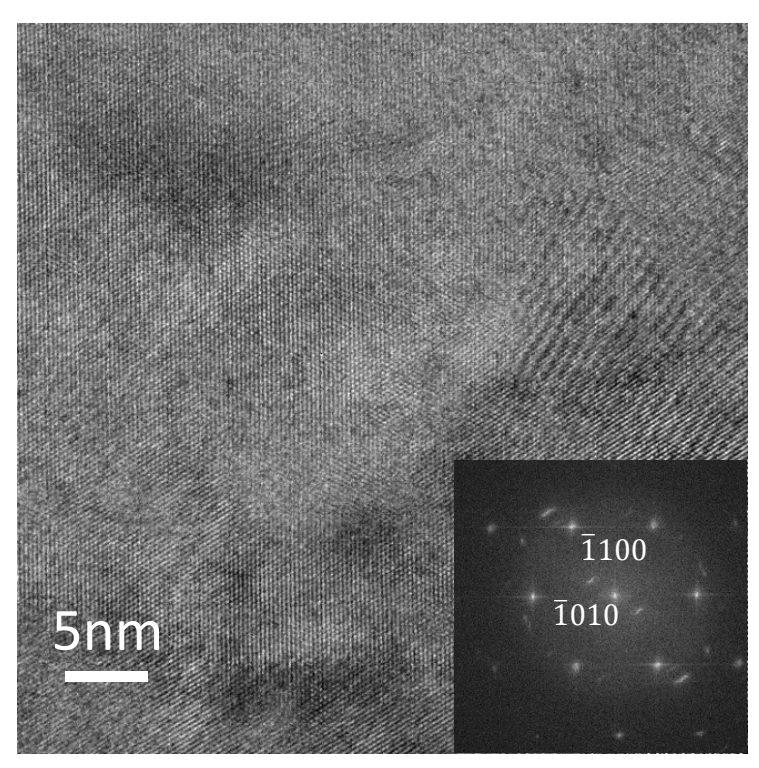

(a)

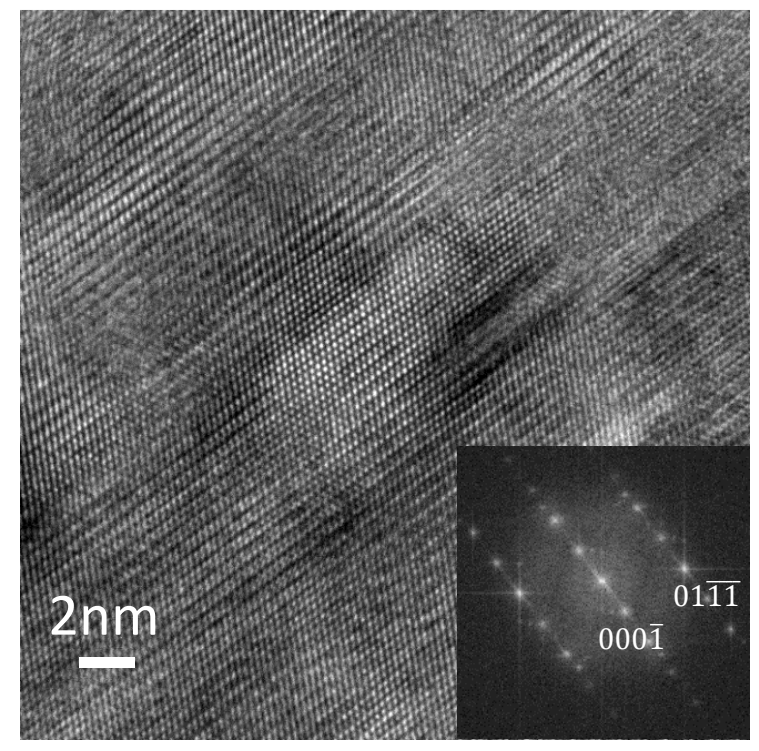

(b)

Fig. 2

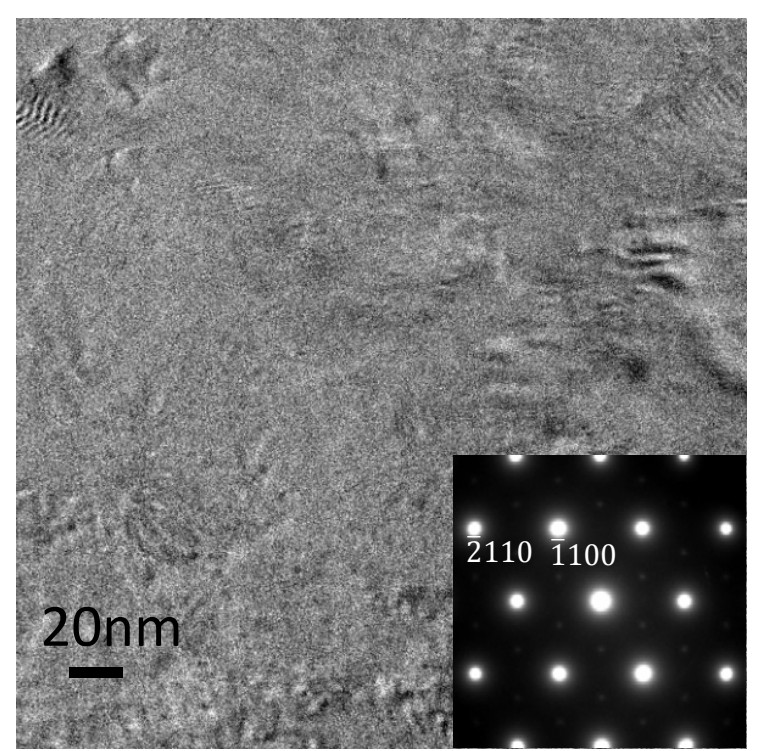

(a)

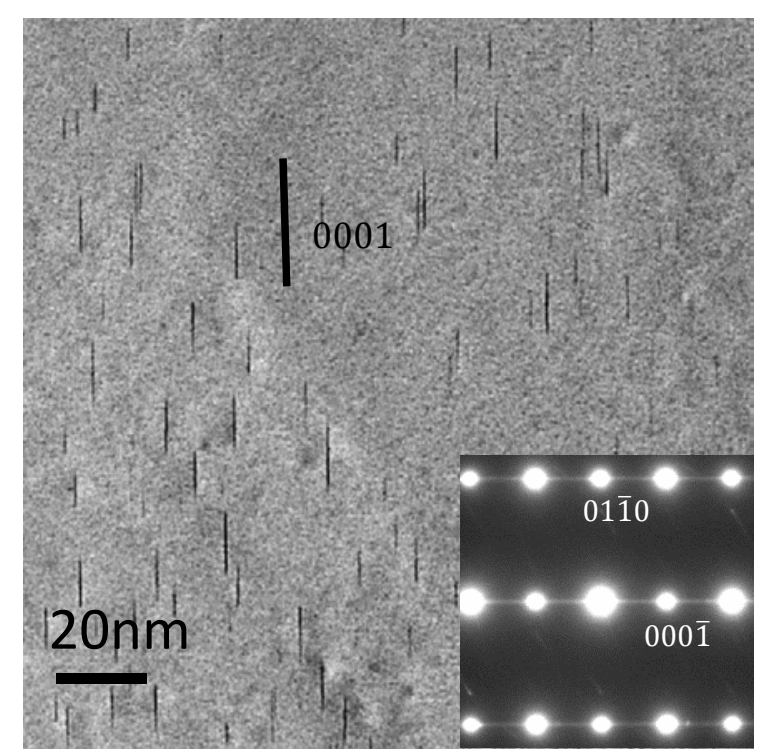

(b) 


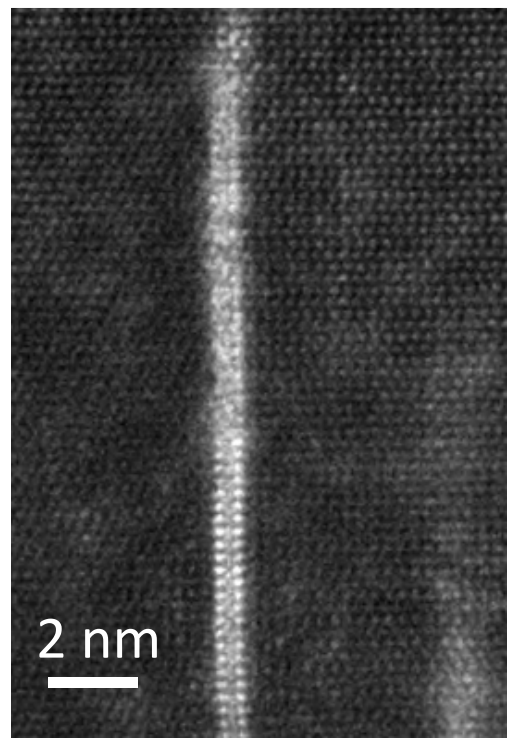

(c)

Fig. 3

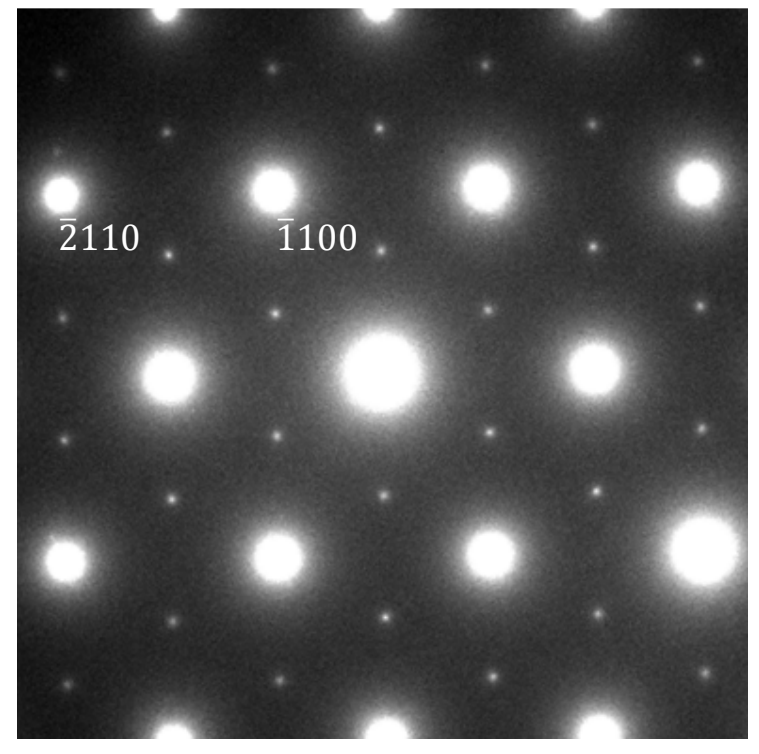

(a)

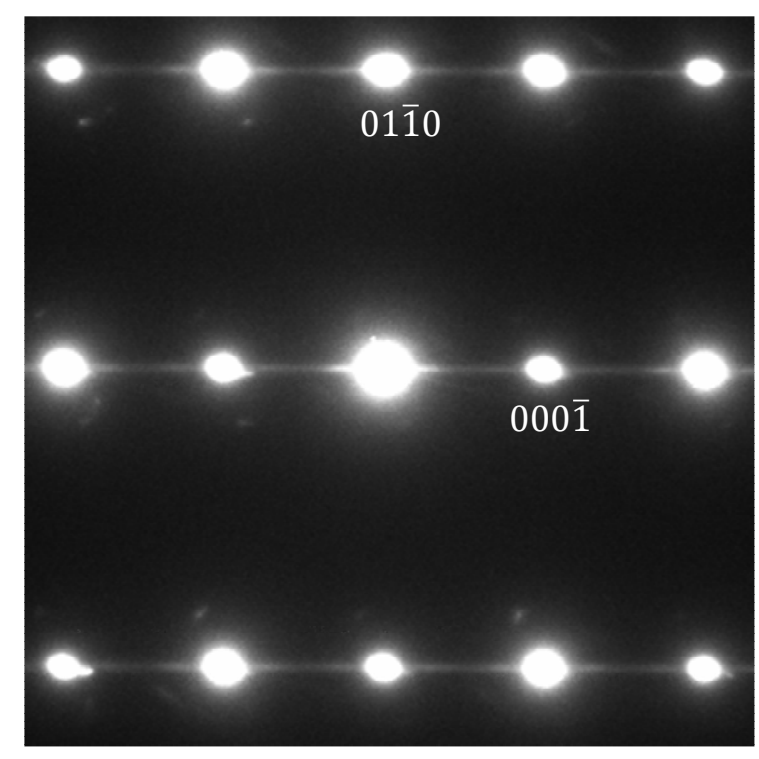

(b) 


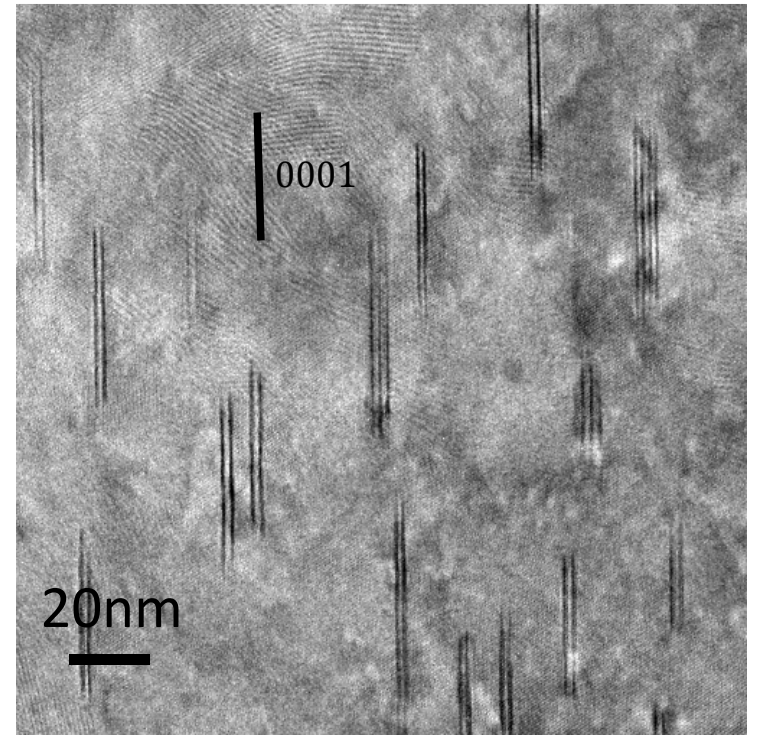

(c)

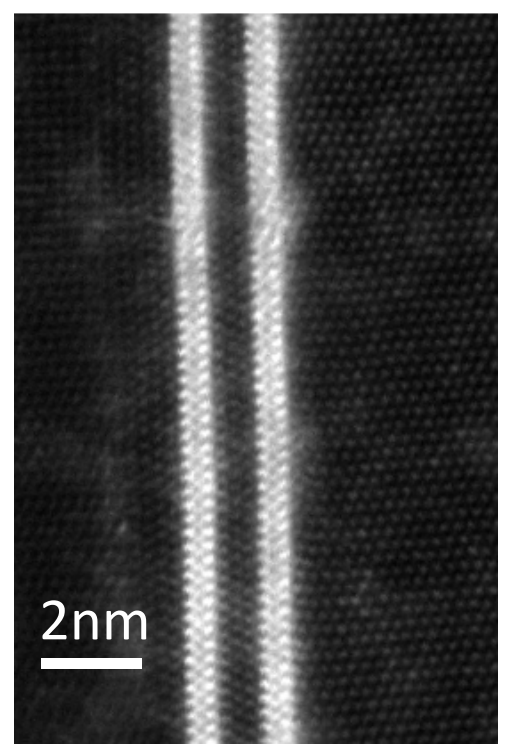

(e)

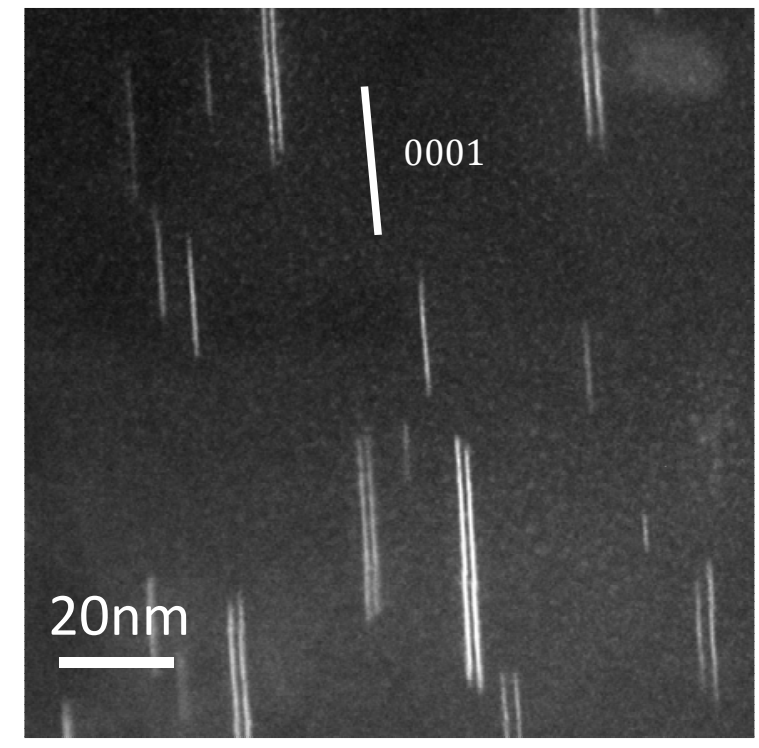

(d)

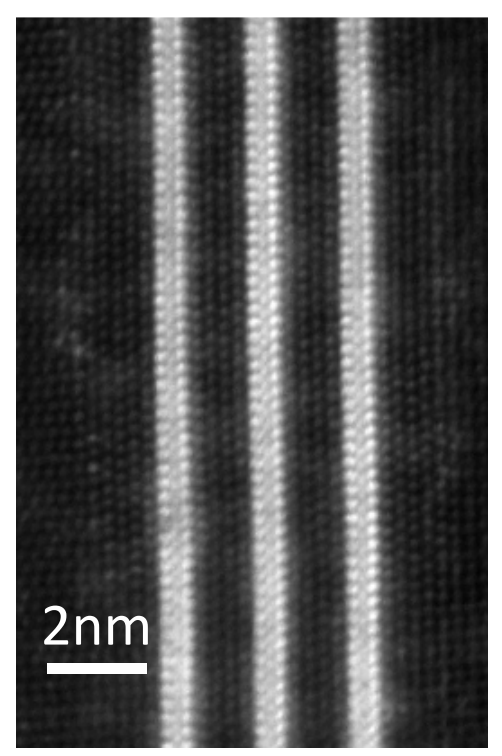

(f)

Fig.4 


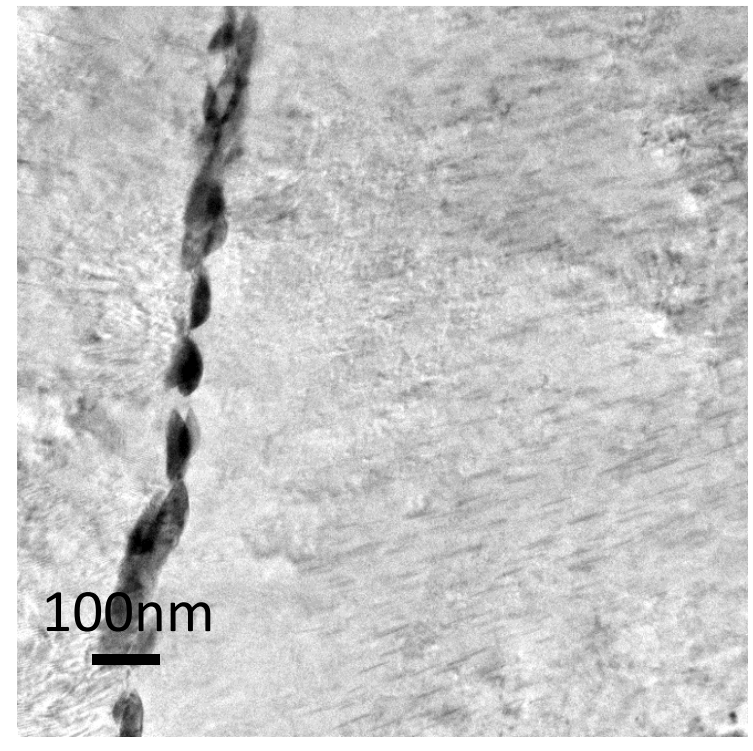

(a)

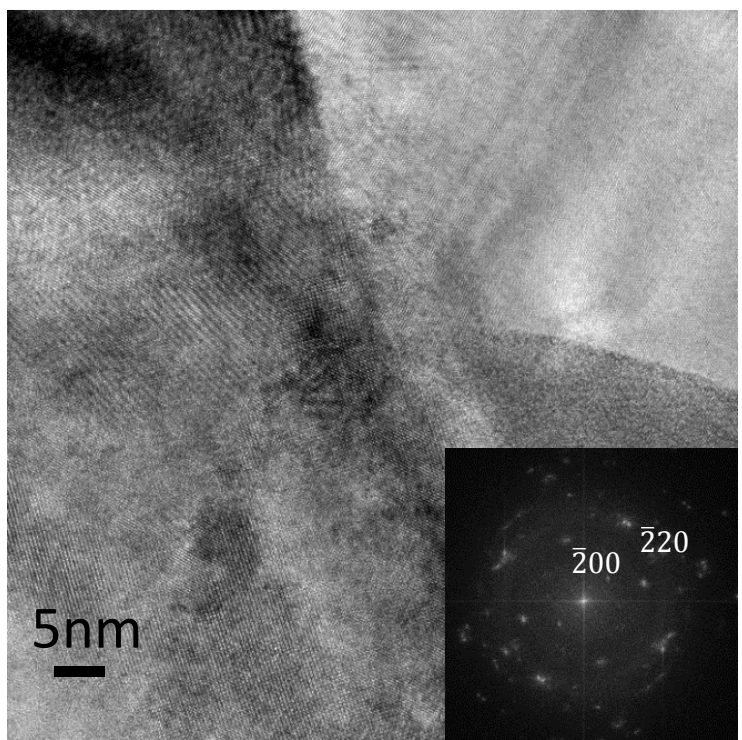

(b)

Fig. 5

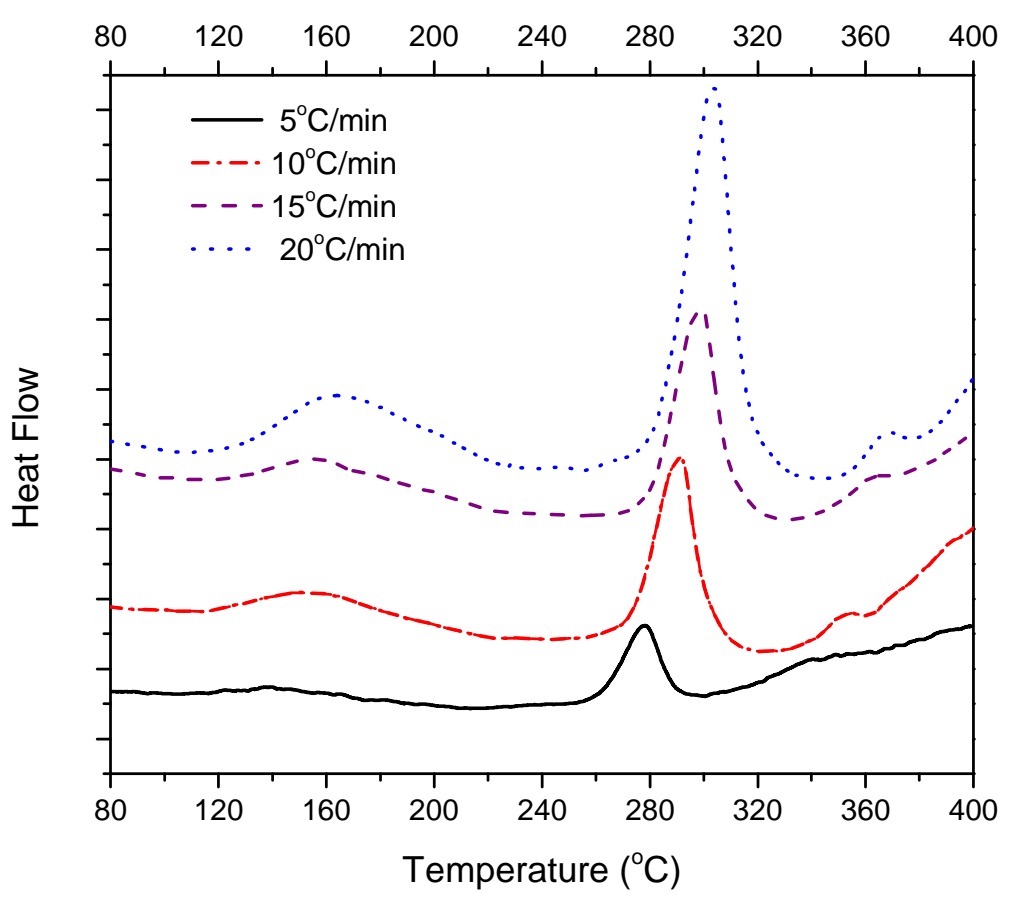

Fig.6 


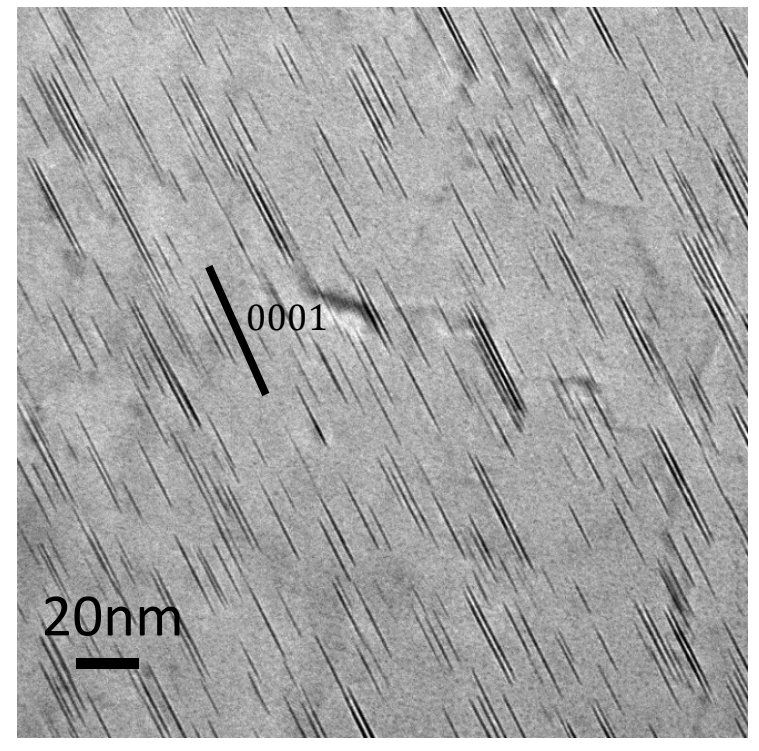

(a)

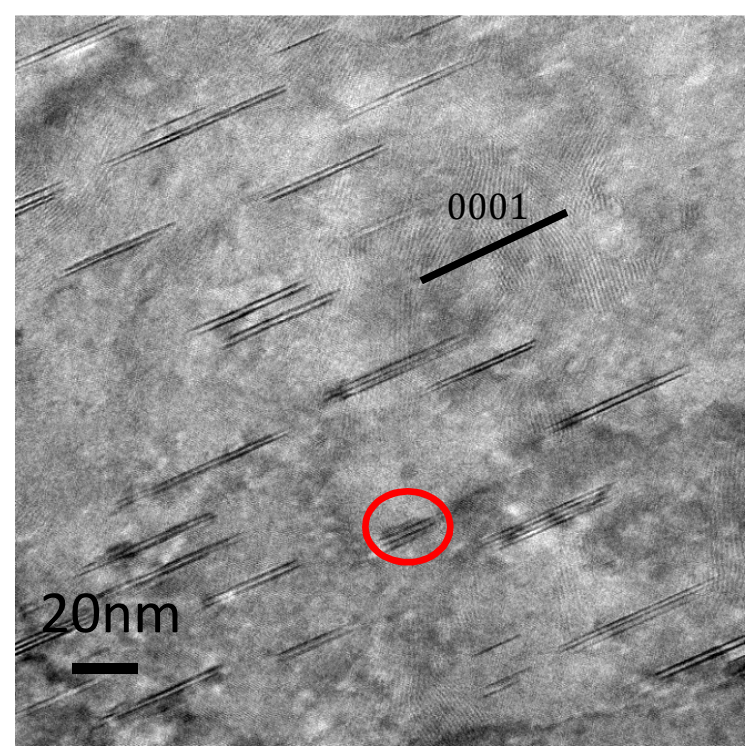

(c)

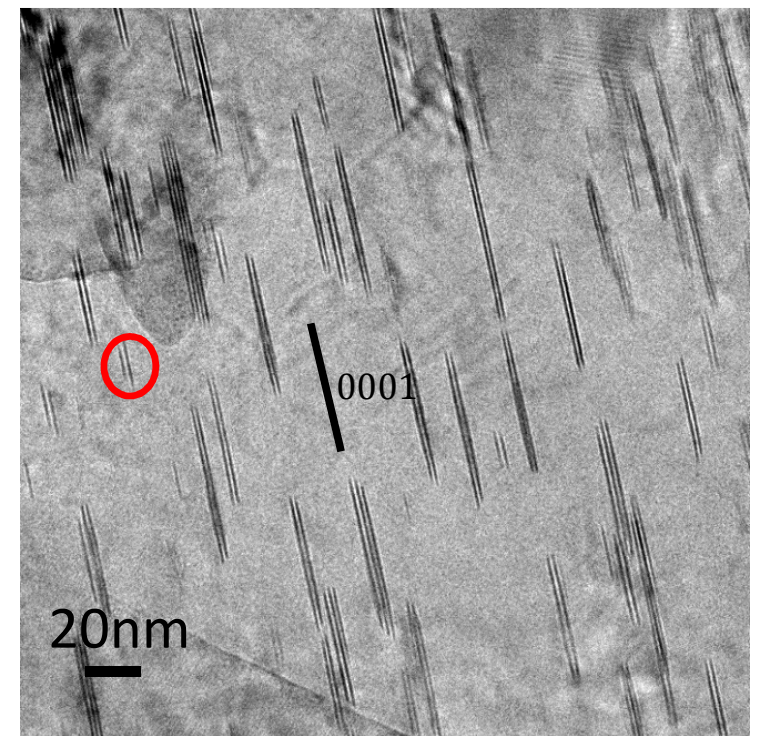

(b)

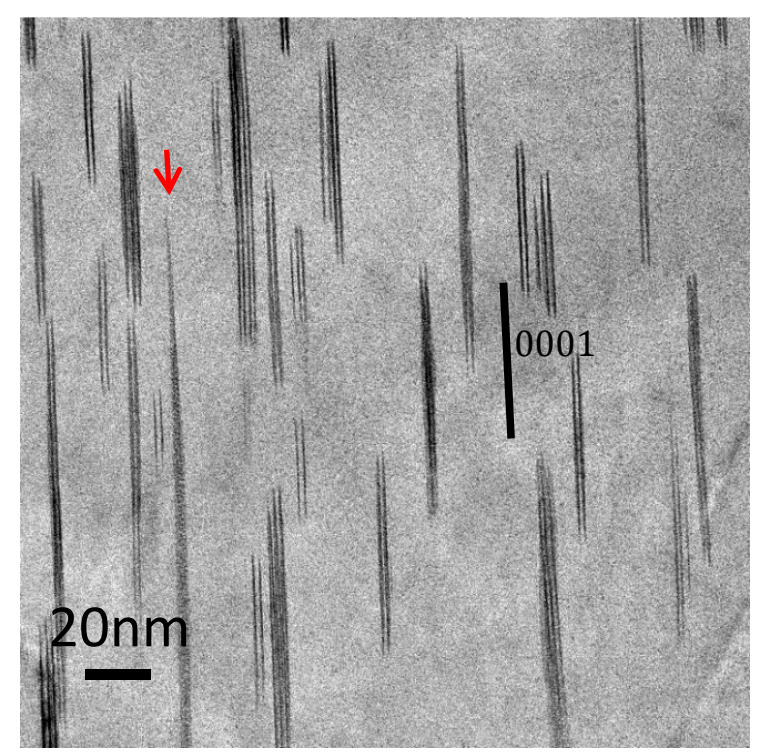

(d)

Fig.7 
Precipitation sequence in a high-zinc magnesium-samarium-zinc-zirconium alloy has been identified;

Structures of metastable precipitates are modified directly with HAADF-STEM;

Kinetic calculations were performed to understand nucleation/growth mechanisms of these precipitates 